EXPERIMENTAL STUDY

\title{
Differential gene expression in pituitary adenomas by oligonucleotide array analysis
}

\author{
Damian G Morris ${ }^{1}$, Mädälina Muşat ${ }^{4}$, Sándor Czirják ${ }^{3}$, Zoltán Hanzély ${ }^{3}$, Debra M Lillington ${ }^{2}$, Márta Korbonits ${ }^{1}$ \\ and Ashley B Grossman ${ }^{1}$ \\ ${ }^{1}$ Department of Endocrinology and ${ }^{2}$ Cancer Research UK, Medical Oncology Unit, St Bartholomew's and the Royal London School of Medicine and \\ Dentistry, London EC1A 7BE, UK, ${ }^{3}$ National Institute of Neurosurgery, 1145 Budapest, Hungary and ${ }^{4}$ Department of Endocrinology, Carol Davila \\ University of Medicine and Pharmacy, Bucharest, Romania \\ (Correspondence should be addressed to A B Grossman; Email: A.B.Grossman@qmul.ac.uk)
}

\begin{abstract}
Objectives: Microarray technology allows for the expression profile of many thousands of genes to be quantified at the same time, and has resulted in novel discoveries about the tumour biology of a number of cancers. We sought to do this in pituitary adenomas, the most common intracranial neoplasm.

Methods: Affymetrix GeneChip HG-U133A oligonucleotide arrays covering 14500 well-characterised genes from the human genome were used to study pooled RNA for each of the four major pituitary adenoma subtypes. Individual gene-expression levels in the tumours were compared relative to the expression profile in normal pooled pituitary RNA. Three differentially expressed genes with potential importance in tumourigenesis were chosen for validation by real-time quantitative PCR on the original tumours and on an additional 26 adenomas.

Results: Bioinformatic analysis showed that 3906 genes and 351 expressed sequence tags were differentially expressed among all pituitary tumour subtypes. Lysosomal-associated protein transmembrane-4- $\beta$ (LAPTM4B), a novel gene upregulated in hepatocellular carcinoma, was significantly over-expressed in adrenocorticotrophin (ACTH)-secreting adenomas and non-functioning pituitary adenomas (NFPAs). Bcl-2-associated athanogene (BAG1), an anti-apoptotic protein found at high levels in a number of human cancers, was significantly over-expressed in growth hormone-secreting and prolactin-secreting adenomas and NFPAs. The cyclin-dependent kinase inhibitor p18, in which murine gene deletion has been shown to produce pituitary ACTH cell hyperplasia and adenomas, was significantly under-expressed in ACTH-secreting adenomas.

Conclusions: Expression array analysis of pituitary adenomas using the Affymetrix GeneChip HGU133A arrays appears to be a valid method of identifying genes that may be important in tumour pathogenesis.
\end{abstract}

European Journal of Endocrinology 153 143-151

\section{Introduction}

Pituitary adenomas account for $10-15 \%$ of all intracranial neoplasms. Despite extensive research, the pathogenesis of the majority of pituitary adenomas remains unsolved. In the majority these are monoclonal, benign, slow-growing neoplasms, and therefore perhaps it is not surprising that studies into many of the common oncogenes or tumour-suppressor genes involved in human cancer have been unrevealing when applied to these tumours. The only common and reproducible mutation to date implicated in pituitary pathogenesis is the $\mathrm{Gs}_{\alpha}$ mutation linked to the growth hormone-releasing hormone receptor (GHRH-R) in approximately one-third of growth hormone $(\mathrm{GH})$-secreting adenomas, leading to constitutive activation and cAMP production (1). However, advances in molecular biology have the potential to fast-track the search for new candidate tumourigenic genes. The foremost of these techniques is expression profiling, by either differential display techniques or microarray analysis. Differential display analysis of rat or human pituitary tumours has resulted in the identification of a number of novel candidate genes, including pituitary tumour-transforming gene (PTTG) (2), growth arrest and DNA damage induced-45 (GADD45) (3), maternally expressed gene 3a (MEG3a) (4) and bone morphogenetic protein 4 (BMP-4) (5). In rodent pituitary adenomas microarray expression analysis has been utilised in three studies $(6-8)$. In human pituitary adenomas there has been only one published study (9), in which the authors used a 
cDNA array that contained 7075 genes to compare the expression profile of a normal pituitary sample to single cases of non-functioning pituitary adenoma (NFPA), and GH-, prolactin (PRL)- and adrenocorticotrophin $(\mathrm{ACTH})$-secreting adenomas: in total, 128 genes were differentially expressed. Of these, three seemed to have oncogenic importance and were examined by realtime quantitative PCR (RQ-PCR) in a further 37 pituitary samples. The orthinine decarboxylase (ODC1) gene was over-expressed in $\mathrm{GH}$-secreting adenomas compared with other tumour types, but was underexpressed in ACTH-secreting adenomas. The C-mer proto-oncogene tyrosine kinase (MERTK) gene was over-expressed in ACTH-secreting adenomas, but was under-expressed in PRL-secreting adenomas. The folate receptor (FR) gene was over-expressed in NFPAs, but was under-expressed in GH- and PRLsecreting adenomas. A subsequent study confirmed the over-expression of the FR at the protein level in NFPAs (10), although it remains to be determined how this is related to tumourigenesis. When searching for potential candidate genes by microarray, the limiting factor is the number of targets represented on each array. In this study we have used the commercially available Affymetrix GeneChip HG-U133A arrays to study pooled RNA from each of the four major pituitary adenoma subtypes: GH-secreting, ACTH-secreting and PRL-secreting pituitary adenomas, and NFPAs. These are in situ-synthesised, high-density oligonucleotide arrays that contain 22284 probe sets encompassing 18400 transcripts and variants, including 14500 well-characterised genes from the human genome. More-detailed information may be found at http://www.affymetrix.com. Expression profiles were compared with that obtained from pooled normal pituitary tissue. Validation of individual gene expression in specific cases was evaluated by RQ-PCR.

\section{Materials and methods}

\section{Tissue specimens}

For the array analysis, it was found that the quantity of high-quality mRNA extractable from a single adenoma was limited; therefore, a total of five human pituitary adenomas of each of the main subtypes (GH-, ACTHand PRL-secreting tumours, and NFPAs) were used to provide the necessary minimum quantity per chip. Five normal human pituitary autopsy specimens obtained from patients with no evidence of any endocrine abnormality and within $12 \mathrm{~h}$ of death were also studied. For the RQ-PCR an additional six GH-, eight ACTH- and five PRL-secreting tumours and seven NFPAs were studied. Tissue samples were collected in liquid nitrogen and then stored at $-80^{\circ} \mathrm{C}$. The tumour type was determined on the basis of clinical and biochemical findings before surgery and by morphological and immunocytochemical analysis of the removed tissue sample.
In order to reduce the possibility of contamination of the tumour tissue by non-adenomatous pituitary tissue during trans-sphenoidal surgery, only GH- and PRL-secreting and NFPA macroadenoma samples (tumours $\geqq 10 \mathrm{~mm}$ diameter) were chosen for analysis. In the case of the ACTH-secreting tumours this was not possible as the majority of tumours are microadenomas $(<10 \mathrm{~mm})$, and macroadenomas are not representative of the average population of patients with Cushing's disease; however, PCR for the non-corticotroph transcription factor Pit-1 was performed on the ACTH-secreting samples and NFPAs to exclude contamination by normal non-adenomatous pituitary tissue, as described previously (11). In addition, RT-PCR for pro-opiomelanocortin (POMC; the ACTH-precursor) to exclude contamination with corticotrophs, present in normal pituitary, was performed on the GH- and PRL-secreting adenomas (11). Informed consent was obtained from all patients, and the study was approved by the local Ethics Committee (Institutional Review Board).

\section{RNA extraction}

Total RNA was extracted from homogenised frozen tissue using an SV isolation kit (Promega, Southampton, UK), which includes a DNase step. The integrity of the total RNA of each sample was determined by denaturing gel electrophoresis, and the mRNA quantified approximately by spectrophotometry.

\section{Target preparation and microarray hybridisation}

Each of the four subtypes of pituitary adenoma and the normal pituitary tissue was studied using a single array: $3 \mu \mathrm{g}$ total RNA from each of the five individual tumours/normal pituitaries was pooled, concentrated by ethanol precipitation and re-quantified. Further template labelling and array hybridisation was as per the Affymetrix GeneChip Eukaryotic sample and array-processing protocol (Affymetrix, Santa Clara, CA, USA). In brief, $10 \mu \mathrm{g}$ pooled total RNA was synthesised to double-stranded cDNA using SuperScript doublestranded-cDNA synthesis reagents (Invitrogen, Paisley, Scotland, UK). T7-(dT) 24 primer (Affymetrix) was used for priming the first-strand cDNA synthesis. Purification of the double-stranded cDNA was by phenol/chloroform extraction utilizing Phase-lock gel tubes (Eppendorf), followed by ethanol precipitation. The cDNA was synthesised to cRNA using the BioArray High Yield RNA Transcript labelling kit (Affymetrix): reactions were carried out at $37^{\circ} \mathrm{C}$ for $5 \mathrm{~h}$, with agitation every $30 \mathrm{~min}$. Clean-up of the cRNA using the RNeasy columns (Qiagen, Crawley, Sussex, UK) was performed to remove unincorporated ribonucleotides, prior to quantification by spectrophotometry. The cRNA was fragmented by metal-induced hydrolysis at $94^{\circ} \mathrm{C}$ for $35 \mathrm{~min}$ in a buffer (final concentrations, $40 \mathrm{mM}$ Tris 
acetate, $\mathrm{pH} 8.1,100 \mathrm{mM}$ potassium acetate and $30 \mathrm{mM}$ magnesium acetate). Adequate cRNA fragmentation was determined by denaturing gel electrophoresis. The hybridisation cocktail $(300 \mu \mathrm{l})$ was prepared from $150 \mu \mathrm{l} 2 \times$ hybridisation buffer (final concentration, $100 \mathrm{mM}$ Mes, $1 \mathrm{M} \mathrm{NaCl}, 20 \mathrm{mM}$ EDTA and $0.01 \%$ Tween 20), $15 \mu \mathrm{g}$ cRNA and $5 \mu \mathrm{l}$ control oligonucleotide B2. Herring sperm and acetylated BSA were added to final concentrations of 0.1 and $0.5 \mathrm{mg} / \mathrm{ml}$ respectively. As external controls (spikes), in vitro transcripts of bacterial genes BioB, BioC, BioD and cre were added to final concentrations of $1.5,5,25$ and 100 pM, respectively. An $80 \mu \mathrm{l}$ aliquot of cocktail was hybridised to a GeneChip Test 3 array (Affymetrix) to examine the target quality, and if this was adequate $200 \mu \mathrm{l}$ cocktail was then hybridised to a GeneChip HG-U133A array. Incubation was performed at $45^{\circ} \mathrm{C}$ for $16 \mathrm{~h}$ with constant rotation at 60 r.p.m. Arrays were washed and stained at an Affymetrix fluidics wash station with streptavidinphycoerythrin (SAPE; Molecular Probes, Eugene, OR, USA). Signal amplification was performed by the use of biotinylated anti-streptavidin antibody (Vector Laboratories, Peterborough, Cambs, UK). Scanning was performed on a GeneArray Scanner (Agilent Technologies, Waldbronn, Germany), and the fluorescence intensities of the scanned arrays were analysed with Affymetrix Microarray Suite 5.0.

\section{Data measurement and transformation}

Using Affymetrix Microarray Suite 5.0 global scaling was applied to the quantification data to adjust the average recorded to a target intensity of 100 . Data were then exported into the bioinformatics software GeneSpring 6.0 (Silicon Genetics, Redwood City, CA, USA) for further analysis. Data normalisation was performed to scale the data so that the average intensity value on each array was 1 , by dividing each expression value by the median of the expression levels on each chip. The individual gene expression levels for each of the four pituitary adenoma subtype arrays was divided by the expression level in the normal pituitary array. Thus, the data are presented as relative to the expression in normal pituitary tissue. Filtering was then performed to identify genes over- or under-expressed at least 2.0-fold in tumours compared with normal pituitary, based on Affymetrix internal quality-control data. The differentially expressed gene data list and experiment raw data are deposited at http://www.ncbi.nlm.nih.gov/geo/ (GEO accession no. GSE 2175). Further analysis as to the potential relevance of differentially expressed genes in tumourigenesis was achieved by use of the PubMed database (http://www.ncbi.nlm.nih.gov/PubMed).

\section{RQ-PCR}

RQ-PCR for the genes of interest was performed on the pooled RNA samples for each of the pituitary tumour subgroups and normal pituitary, the RNA of each of the individual samples, and also RNA of the additional 26 pituitary adenomas. Total RNA $(1 \mu \mathrm{g})$ was reversetranscribed into cDNA using TaqMan reverse transcription reagents (Applied Biosytems, Warrington, Cheshire, UK). Each $50 \mu \mathrm{l}$ reaction mix contained $5.5 \mathrm{mM}$ $\mathrm{MgCl}_{2}, 2 \mathrm{mM}$ dNTP mix, $2.5 \mu \mathrm{M}$ random hexamers, 20 U RNase inhibitor, 62.5 U Multiscribe reverse transcriptase and $1 \mu \mathrm{g}$ RNA. Thermal cycling conditions were as follows: $25^{\circ} \mathrm{C}$ for $10 \mathrm{~min}, 48^{\circ} \mathrm{C}$ for $30 \mathrm{~min}$ and $95^{\circ} \mathrm{C}$ for $5 \mathrm{~min}$.

The RQ-PCR reactions and analysis were carried out using the ABI Prism 7900 Sequence Detection System (Applied Biosytems), which allows for detection of PCR products as they accumulate during the PCR process, rather than assaying the final product after a fixed number of cycles. For each experiment a RQ-PCR for the endogenous control gene $18 \mathrm{~S}$ rRNA was also performed for each sample, allowing data to be expressed relative to $18 \mathrm{~S}$ rRNA, therefore compensating for any differences in reverse transcriptase efficacy. We had previously determined $18 \mathrm{~S}$ rRNA to be the most consistent internal control gene in pituitary tissue, both adenomatous and normal, using the TaqMan Human Endogenous Control Plate (Applied Biosytems) (12). To allow for comparison between RQ-PCR experiments, standard curves were constructed for the genes of interest and $18 \mathrm{~S}$ rRNA using human paraganglioma total RNA (lysosomal-associated protein transmembrane-4- $\beta$ (LAPTM4B) and p18) or human prolactinoma total RNA (Bcl-2-associated athanogene (BAG1)), which were shown to have significant expression of the respective genes. Serial 5-fold dilutions $(20 \mathrm{ng} / \mu \mathrm{l}-32 \mathrm{pg} / \mu \mathrm{l})$ in TE buffer were performed followed by reverse transcription, and these stocks of cDNAs were used for all experiments. Data from standard curves with a correlation coefficient of less than 0.97 were discounted. RQ-PCR was carried out in triplicate using $10 \mu \mathrm{l}$ reaction volumes containing $5 \mu \mathrm{l}$ TaqMan $2 \times$ PCR Master Mix, $200 \mathrm{nM} 18 \mathrm{~S}$ rRNA or $250 \mathrm{nM}$ LAPTM4B, BAG1 and p18 probe, $300 \mathrm{nM} 18 \mathrm{~S}$ rRNA or $900 \mathrm{nM}$ LAPTM4B, BAG1 and p18 forward primer, $300 \mathrm{nM} 18 \mathrm{~S}$ rRNA or $900 \mathrm{nM}$ LAPTM4B, BAG1 and p18 reverse primer, at $50^{\circ} \mathrm{C}$ for $2 \mathrm{~min}$ and $95^{\circ} \mathrm{C}$ for $10 \mathrm{~min}$ followed by 40 cycles of $95^{\circ} \mathrm{C}$ for $15 \mathrm{~s}$ and $60^{\circ} \mathrm{C}$ for $1 \mathrm{~min}$.

Primer and probes were synthesised by MWG Biotech, Germany (18 S rRNA) or Applied Biosystems (LAPTM4B, BAG1 and p18) with sequences as follows: $18 \mathrm{~S}$ rRNA (GenBank accession no. X03205), forward 5'-TCCCCATGAACGAGGAATTC-3', reverse 5'-GTGTACAAAGGGCAGGGACTTAA-3', probe 5'-CAACGCAAGCTTATGACCCGCACTTACT-3'; LAPTM4B (GenBank accession no. NM018407), forward 5'-CTGGGAGGTGACTTTGAGTTCAT-3', reverse 5'-AGAGAAATCGCAATGGCAATGC- $3^{\prime}$, probe 5'-ACATGTTGGCATCATCC-3'; BAG1 (GenBank accession no. NM004323), forward 5'-CTGACCAGCTGGAAGAGTTGAATAA-3', reverse 5'AGAGCTTCAGCTTGCAAATCCTT-3', probe 5'-CCAGCA- 
GGGTTTTCTCTGCAGGTTATGAAACTT-3'. The probes for LAPTM4B, BAG1 and p18 were conjugated with a minor groove binder. Probes were labelled with the reporter dye (6-carboxy-fluorescein, FAM) at the $5^{\prime}$-end and a non-fluorescent quencher for LAPTM4B, BAG1 and p18 or with the fluorescent dye 6-carboxy-tetramethylrodamine (TAMRA) at the $3^{\prime}$ end for $18 \mathrm{~S}$ rRNA. Experiments were performed on at least two occasions for each sample.

\section{Statistical analysis}

Data were expressed as the ratio of gene quantity to $18 \mathrm{~S}$ rRNA quantity. Data are shown as medians with minimum and maximum values, and 25th and 75 th percentile values. The non-parametric Kruskal-Wallis analysis of variance was used to calculate differences in expression between groups of tissues. Significance was taken as $P<0.05$.

\section{Results}

Using the Affymetrix GeneChip HG-U133A oligonucleotide array the expression profiles of each of the four major pituitary adenoma subtypes were obtained and compared with the expression profile of normal autopsy pituitary tissue. In total, 3906 genes and 351 expressed sequence tags (ESTs) were differentially expressed among all the pituitary adenoma subtypes. There were 47 genes and a single EST that were overexpressed uniformly in all the adenoma subtypes, and 127 genes and five ESTs that were under-expressed in all the adenoma subtypes.

\section{Expression profile of GH-secreting adenomas}

In the GH-secreting adenoma array 401 genes and 26 ESTs were over-expressed $\geqq 2$.0-fold, and 921 genes and 80 ESTs were under-expressed $\geqq 2$.0-fold. Compared with other tumour types 135 genes were uniquely over-expressed, and 352 genes uniquely under-expressed. Consistent with the adenoma subtype, $\mathrm{GH}$ was the most highly uniquely expressed gene, and the GHRH-R was over-expressed 9.6-fold. Similarly, POMC, the corticotrophin-releasing hormone receptor (CRH-R), PRL, luteinising hormone (LH), follicle-stimulating hormone (FSH) and thyroid-stimulating hormone (TSH) were under-expressed >10-, 4.5-, 6.5-, 8.0-, 3.6- and >10-fold, respectively.

\section{Expression profile of ACTH-secreting adenomas}

In the ACTH-secreting adenoma array 1016 genes and 76 ESTs were over-expressed $\geqq 2$.0-fold, and 634 genes and 56 ESTs were under-expressed $\geqq 2$.0-fold. Compared with other tumour types 520 genes were uniquely over-expressed, and 179 genes uniquely under-expressed. Consistent with the adenoma subtype,
POMC was the most highly expressed gene, and CRH-R and the glucocorticoid receptor (GR) were overexpressed 3.0- and 2.5-fold, respectively. Similarly, Pit1, PRL, GH, GHRH-R, LH and TSH were under-expressed 4.4-, 2.4-, >10-, 3.9-, >10- and >10-fold respectively.

\section{Expression profile of NFPAs}

In the NFPA array 890 genes and 52 ESTs were overexpressed $\geqq 2$.0-fold, and 937 genes and 123 ESTs were under-expressed $\geqq 2$.0-fold. Compared with other tumour types 467 genes were uniquely overexpressed, and 370 genes uniquely under-expressed. Consistent with the non-secretory nature of this adenoma subtype, POMC, GH, PRL, LH and TSH were under-expressed $>10-,>10-,>10-, 7.7-$ and $>10-$ fold respectively. However, FSH was over-expressed 7.4-fold. In addition, the CRH-R and GHRH-R were under-expressed 9.4- and 4.1-fold respectively.

\section{Expression profile of PRL-secreting adenomas}

In the PRL-secreting adenoma array 663 genes and 43 ESTs were over-expressed $\geqq 2$.0-fold, and 816 genes and 53 ESTs were under-expressed $\geqq 2$.0-fold. Compared with other tumour types 275 genes were uniquely over-expressed, and 282 genes uniquely under-expressed. Consistent with the adenoma subtype, PRL was the most highly expressed gene, and Pit-1 was over-expressed 3.7-fold. Similarly, POMC, CRH-R, GR, GH, GHRH-R, LH, FSH and TSH were under-expressed $>10-$, 4.3-, 4.1-, 10-, 7.8-, >10-, 2.0- and >10-fold respectively.

\section{Identification of potential candidate genes}

The criteria used for under- and over-expression was a 2-fold difference in expression levels from normal. Very few genes were over-expressed by more than 5-fold in any tumour type (122 of the 2456 genes over-expressed in one or more tumour subtype). Indeed, the majority of genes are only over-expressed 2.0-3.0-fold (e.g. 89\% in GH-secreting tumours, $80 \%$ in PRL-secreting tumours). Similarly, the majority of under-expressed genes were in the 2.0-3.0-fold range. Whereas it was hoped that the more highly differentially expressed genes might yield plausible candidate genes, this did not appear to be the case. Therefore it was necessary to concentrate on more modestly over-/under-expressed genes. Thus three differentially-expressed genes with potential tumourigenic significance, not previously associated with pituitary tumourigenesis, were chosen: LAPTM4B was over-expressed 2.4-fold in the ACTH-secreting adenoma array and 2.3-fold in PRL-secreting adenoma array. LAPTM4B is a recently described integral membrane protein with four transmembrane domains that has been shown to be upregulated at the mRNA and protein level in hepatocellular carcinoma and a number of 
other human cancer cell lines (13). Transfection of the LAPTM4B gene into murine 3T3 fibroblasts caused cell proliferation by regulation of cell-cycle control involving upregulation of cyclin $\mathrm{E}$ and increased transition of cells into S phase (14).

BAG1 was over-expressed 2.7-fold in the GH-secreting adenoma array and 5.0-fold in the PRL-secreting adenoma array. BAG1 is a multifunctional protein that blocks apoptosis and regulates other diverse pathways involved in cell proliferation and stress responses: BAG1 protein has been found to be over-expressed in a number of human cancers.

The cyclin-dependent kinase (CDK) inhibitor 2C, or p18, was under-expressed 3.2-, 2.6- and 2.2-fold in the GH-secreting adenoma, NFPA and PRL-secreting adenoma arrays, respectively. Through binding and inhibiting CDKs 4 and 6, and thereby preventing cyclin D-dependent phosphorylation of retinoblastoma, p18 is a negative regulator of the cell cycle. Murine gene deletion of p18 has been shown to produce pituitary ACTH cell hyperplasia and adenomas (15). These three genes were subject to further validation by RQ-PCR.

\section{RQ-PCR for LAPTM4B, BAG1 and p18}

In order to validate the expression patterns of the genes LAPTM4B, BAG1 and p18 as shown by microarray, RQ-PCR was performed on the pooled RNA from the tumours and normals. The results for LAPTM4B confirmed a $>2$ fold over-expression in the pooled ACTHand PRL-secreting adenoma RNAs (Fig. 1A). Similarly, BAG1 was confirmed as over-expressed by RQ-PCR in both pooled GH- and PRL-secreting RNAs, but it also appeared to be over-expressed in the pooled NFPA RNA (Fig. 1B). For p18 there was poor correlation, and it appeared to be under-expressed only in the pooled ACTH-secreting adenoma RNA (Fig. 1C).

These findings were essentially confirmed when RQPCR was performed on an additional 26 pituitary adenomas. In summary, RQ-PCR on 46 pituitary adenomas (11 GH-, 13 ACTH- and 10 PRL-secreting adenomas, and 12 NFPAs) showed that LAPTM4B was significantly overexpressed in ACTH-secreting adenomas $(P=0.007)$ and NFPAs ( $P=0.02$; Fig. $2 A)$; BAG1 was significantly over-expressed in GH- $(P=0.005)$ and PRL-secreting $(P=0.007)$ adenomas and NFPAs $(P=0.01$; Fig. $2 B)$, while p18 was significantly under-expressed in ACTHsecreting adenomas $(P=0.04)$ compared with normal pituitary tissue ( $n=5$; Fig. $2 \mathrm{C})$. Side-by-side comparison of the expression profiles of the genes by RQ-PCR (pooled and total tumours) and microarray is given in Table 1.

\section{Discussion}

The aim of this study was to identify novel differentially expressed genes in pituitary adenomas compared with normal pituitary that may be important candidates in the pathogenesis of these poorly understood tumours. In addition, the ability to study the expression profile of over 14000 genes simultaneously is a powerful analytical tool that should in principle help unravel the complex molecular changes present in the change from normal pituitary tissue to adenoma. The purpose of using pooled RNA for the microarray analysis was to try and improve the specificity of gene-expression results within each tumour subtype, and also within the normal pituitary tissue, without the need to use multiple arrays. This experimental design appeared to be largely validated in the over-expressed genes LAPTM4B and BAG1, although it is apparent by the RQ-PCR results on the individual tumour samples pooled that within tumour subtypes there is marked variability in the expression levels for certain genes (Fig. 1). This seems to have skewed some of the microarray results (e.g. LAPTM4B expression in PRL-secreting tumours), but not others (e.g. BAG1 expression in $\mathrm{GH}-$ secreting tumours), when judged by RQ-PCR validation on the larger group of tumours (Table 1). A demonstration of the robust nature of this novel technology is the remarkable similarity of the results compared with RQ-PCR results from the cDNA array study published by Evans and colleagues (9): they showed (i) that MERTK was over-expressed in ACTH-secreting adenomas up to 13-fold, but was under-expressed in PRL-secreting adenomas, (ii) that the FR gene was over-expressed in NFPAs up to 30-fold, but was under-expressed in

Table 1 Side-by-side comparison of the expression profiles of the genes LAPTM4B, BAG1 and p18 as measured by (1) microarray analysis, (2) RQ-PCR of the pooled sample RNA and (3) RQ-PCR of the total pituitary tumours for each of the pituitary adenoma subtypes.

\begin{tabular}{|c|c|c|c|c|c|c|c|c|c|}
\hline & \multicolumn{3}{|c|}{ LAPTM4B expression } & \multicolumn{3}{|c|}{ BAG1 expression } & \multicolumn{3}{|c|}{ p18 expression } \\
\hline & Microarray & $\begin{array}{l}\text { RQ-PCR } \\
\text { pooled }\end{array}$ & $\begin{array}{c}\text { RQ-PCR } \\
\text { total }\end{array}$ & Microarray & $\begin{array}{l}\text { RQ-PCR } \\
\text { pooled }\end{array}$ & $\begin{array}{c}\text { RQ-PCR } \\
\text { total }\end{array}$ & Microarray & $\begin{array}{l}\text { RQ-PCR } \\
\text { pooled }\end{array}$ & $\begin{array}{c}\text { RQ-PCR } \\
\text { total }\end{array}$ \\
\hline NFPA & 0 & 0 & + & 0 & + & + & - & 0 & 0 \\
\hline $\mathrm{GH}$ & 0 & 0 & 0 & + & + & + & - & 0 & 0 \\
\hline ACTH & + & + & + & 0 & + & 0 & 0 & - & - \\
\hline PRL & + & + & 0 & + & + & + & - & 0 & 0 \\
\hline
\end{tabular}

$0=$ No change in expression relative to normal pituitary; $+=$ over-expression relative to normal pituitary; $-=$ under-expression relative to normal pituitary. 


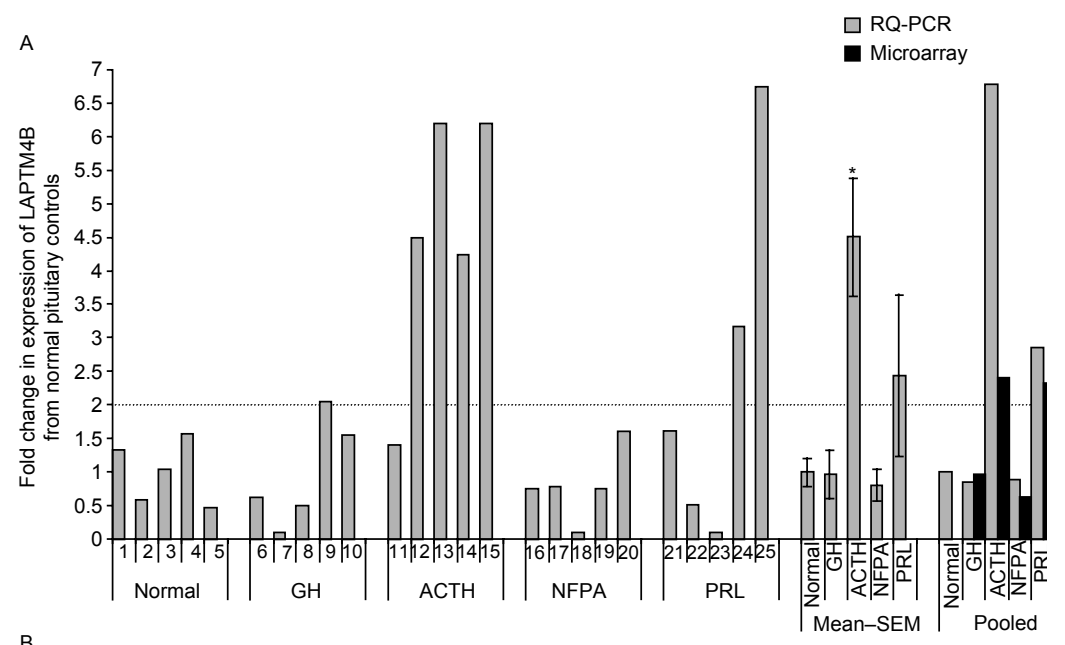

B

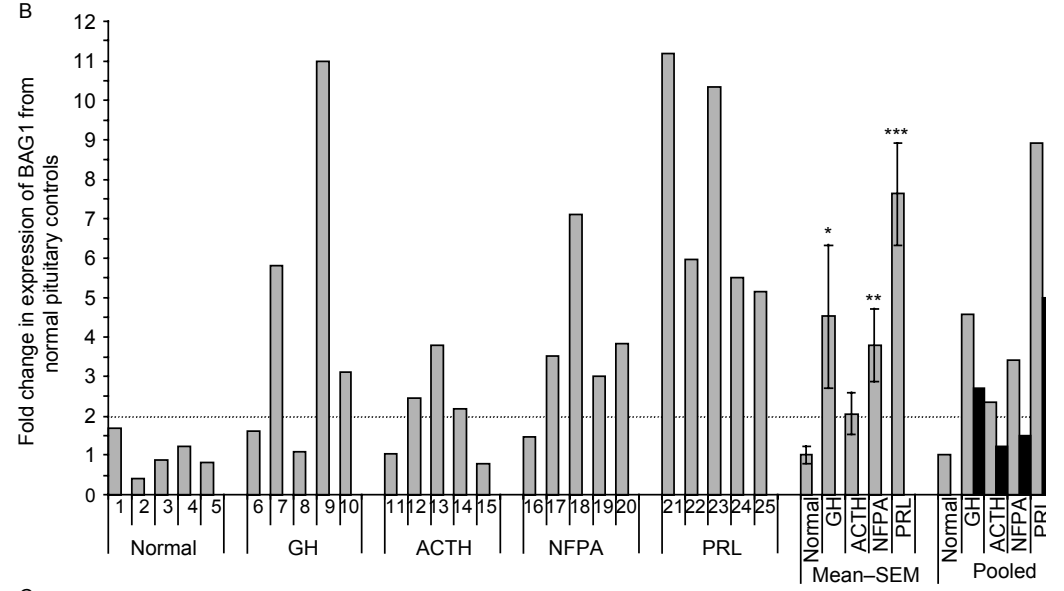

C

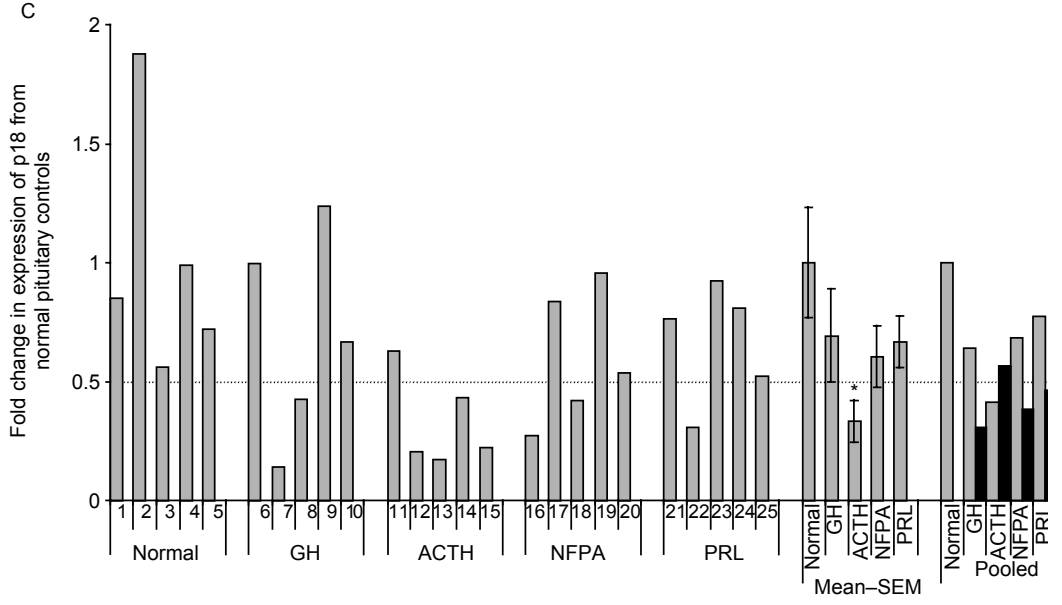

Figure 1 Graphs showing the fold change in mRNA expression levels by RQ-PCR of LAPTM4B (A), BAG1 (B) and p18 (C) in the pooled normal pituitary and pituitary adenoma samples studied by Affymetrix GeneChip HG-U133A oligonucleotide array (right), and also the individual samples from which the pooled samples were formed (left). Gene-expression levels in each sample were normalised to the expression of the internal control $18 \mathrm{~S}$ rRNA in the same sample. For the pooled samples the fold change in expression from normal pituitary controls was calculated by dividing the pooled adenoma expression value by the pooled normal pituitary expression value, and in the case of the individual samples the expression value divided by the mean of the expression values for the five normal pituitary samples. The levels of gene expression by Affymetrix array in the pooled adenoma samples are given for comparison (black bars). The dotted lines represent the cut-off for over- or underexpression. LAPTM4B was significantly overexpressed in ACTH-secreting adenomas $\left({ }^{*} P=0.02\right)$. BAG1 was significantly overexpressed in $\mathrm{GH}$-secreting adenomas $\left({ }^{\star} P=0.008\right)$, NFPAs $\left({ }^{\star *} P=0.006\right)$ and PRLsecreting adenomas $(* * * P<0.0001)$. p18 was significantly underexpressed in $\mathrm{ACTH}$ secreting adenomas $\left({ }^{\star} P=0.009\right)$. The non-parametric Kruskal-Wallis analysis of variance was used to calculate differences in expression between groups.
GH- and PRL-secreting adenomas; and (iii) that the ODC1 gene was over-expressed in GH-secreting adenomas compared with other tumour types but not normal pituitary, but was under-expressed in ACTHsecreting adenomas compared with normal, GH-secreting adenomas and NFPAs (9). On the Affymetrix GeneChip HG-U133A array MERTK was over-expressed in ACTH-secreting adenomas 6.4-fold, and underexpressed 2.5-fold in PRL-secreting tumours, whereas the FR was over-expressed in NFPAs 13-fold and underexpressed in GH- and ACTH-secreting adenomas (2.1and 2.3-fold respectively); there was a trend towards under-expression in the PRL-secreting adenomas (1.69-fold), but it did not meet our cut-off criterion. ODC was under-expressed in the ACTH-secreting adenoma compared with the GH-secreting adenomas (2.2fold), but not compared with normal pituitary or NFPAs. In addition, vimentin was under-expressed in 

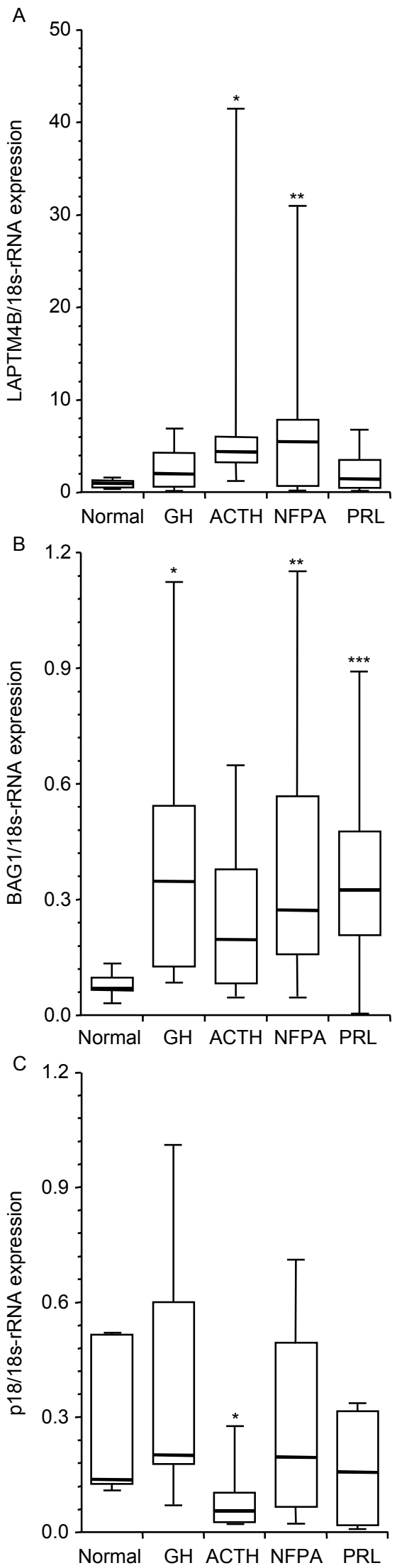

all tumour types in our study as demonstrated previously by the cDNA array study. We were also interested to analyse the gene-expression results obtained by oligonucleotide array of other candidate pituitary genes previously identified by other technologies. PTTG was overexpressed in ACTH-secreting adenomas (3.4-fold), but was not significantly different from normal pituitary in NFPAs or GH- and PRL-secreting tumours (1.6-, 0.8and 1.4-fold, respectively). This is at odds with the results from McCabe et al. (16), which showed PTTG to be overall significantly over-expressed in NFPAs and GH-secreting tumours, although interestingly the highest expression levels were in ACTH-secreting adenomas. However, it should be noted that a significant number of individual pituitary tumours have expression levels $<2$-fold above normal pituitary (17). It was more difficult to make correlations with other reported genes: MEG3a transcript was not represented on the array; GADD45 $\gamma$ did not appear to be expressed in our normal pituitary sample; and BMP-4 was absent from normal pituitary and all tumour types. In addition, we have recently identified Akt1 and Akt2 to be over-expressed in pituitary adenomas, and in particular NFPAs (18). This correlates with the microarray data on Akt1, which show a 2.5 -fold over-expression in NFPAs. Unfortunately, Akt2 is not represented on the HG-U133A array.

Our results show that LAPTM4B is differentially over-expressed in ACTH-secreting adenomas and NFPAs. Several studies indicate that LAPTM4B plays an important role in tumourigenesis $(13,14,19)$, although its exact mechanism of action remains to be elucidated. The over-expression in ACTH-secreting tumours demonstrated by the microarray analysis and confirmed with the RQ-PCR analysis of grouped tumours may relate to the abundant lysosomes present in corticotroph adenomas (20). It should be noted that differences in gene expression between normal pituitary and ACTH-secreting tumours may possibly be due to differences in the clonal composition between the samples, in that in the normal pituitary corticotroph cells represent less than $20 \%$ of the total cells, and in ACTH-secreting adenomas greater than $80 \%$.

Figure 2 Graphs showing the mRNA expression levels of LAPTM4B (A), BAG1 (B) and p18 (C) in normal pituitary $(n=5)$, $\mathrm{GH}$-secreting adenomas $(n=11), \mathrm{ACTH}$-secreting adenomas $(n=13)$, NFPAs $(n=12)$ and PRL-secreting adenomas $(n=10)$ by RQ-PCR. The whiskers represent the maximum and minimum values, the boxes represents the 25th and 75 th percentile ranges of values, and the thick line in each box represents the median value. LAPTM4B was significantly over-expressed in ACTHsecreting adenomas $\left({ }^{\star} P=0.007\right)$ and NFPAs $\left({ }^{\star \star} P=0.02\right)$ compared with normal pituitary tissue. BAG1 was significantly overexpressed in $\mathrm{GH}$-secreting adenomas $\left({ }^{*} P=0.005\right)$, NFPAs $\left({ }^{* *} P=0.01\right)$ and PRL-secreting adenomas $(* \star * P=0.007)$ compared with normal pituitary tissue. p18 was significantly underexpressed in ACTH-secreting adenomas $\left({ }^{\star} P=0.04\right)$ compared with normal pituitary tissue. The non-parametric Kruskal-Wallis analysis of variance was used to calculate differences in expression between groups. 
BAG1 was significantly over-expressed in GH- and PRL-secreting adenomas; this was confirmed by the RQ-PCR analysis, which also suggested over-expression in the NFPAs. In addition to enhancing the antiapoptotic effects of the proto-oncogene Bcl-2 (21), BAG1 augments the activity of several other proteins important in oncogenesis $(22,23)$. BAG1 protein is found to be over-expressed in a number of human cancer cell lines, including breast, colon, leukaemia/lymphoma and prostate (24). In a recent study injection of human breast cancer cells transfected with BAG1 into mouse mammary fat pads resulted in larger tumours than controls (25). It remains to be determined what the protein expression of BAG1 is in pituitary adenomas, and whether transfection of BAG1 into pituitary adenoma cells affects growth.

We found that the CDK inhibitor p18 was significantly under-expressed in various tumour types, although RQPCR analysis did not confirm this, and instead indicated significant under-expression only in ACTH-secreting adenomas; this latter finding was confirmed in the grouped tumour data. The reasons for this discrepancy are unclear, but may possibly be due to error from small differences in fluorescence values at low levels, as the actual expression value of p18 in the normal pituitary was below the median expression value and therefore expression levels in the tumours were even lower. It is interesting to note that in their study Evans and colleagues (9) also showed less good correlation between microarray and RQ-PCR results when genes were under-expressed as opposed to when they were overexpressed (9). Members of the INK4 family of CDK inhibitors, which includes p16 (INK4A) and p18 (INK4C), specifically bind to CDK4 and CDK6, and prevent cyclin D-dependent phosphorylation of retinoblastoma and progression through the cell cycle. Under-expression of p16 mRNA and protein is well described in human pituitary tumours $(26,27)$, and this has been shown to be due to DNA methylation, at least in NFPAs (28). Our microarray results also confirmed p16 to be underexpressed in ACTH- and PRL-secreting tumours and NFPAs by 2.4-, 2.8- and 3.4-fold, respectively. A mouse model with deletion of p18 was created by Franklin and colleagues in 1998, these mice developing widespread organomegaly. Of particular interest was the progressive development of intermediate and anterior pituitary lobe hyperplasia leading to the development of intermediate lobe adenomas by 10 months of age. These adenomas stained strongly for ACTH (15). The same study also demonstrated that mice lacking both p18 and p27 (a member of the KIP family of CDK inhibitors) invariably died from pituitary adenomas by 10 months, suggesting that these two genes mediate two separate pathways to suppress pituitary tumourigenesis. We have previously demonstrated low levels of nuclear p27 in corticotroph tumours compared with other tumour types (29). If it is confirmed that p18 is also under-expressed at the protein level in corticotroph tumours, it would suggest that these tumours are relatively deficient in both p27 and p18, which may synergise, as in the mouse model, in pituitary tumourigenesis. It maybe that alterations in p18 expression, like p16, are influenced by gene methylation.

In conclusion, we have determined the expression profile of more than 14000 genes in the four major subtypes of human pituitary adenomas. This shows that many thousands of genes are differentially expressed compared with normal non-adenomatous pituitary tissue. We have confirmed by RQ-PCR that three genes with potential tumourigenic significance, LAPTM4B, BAG1 and p18, are dysregulated at the mRNA level in pituitary tumours. Further investigation is required into the protein expression and functional relevance of these three genes in pituitary adenomas, and the search for other potential candidate genes continues.

\section{Acknowledgements}

This project was funded in part by donations from the Bart's Foundation for Research and the St Bartholomew's \& Royal London Charitable Foundation, and the Jennifer Davidson Memorial Fund for Research into Cushing's Disease. M K is supported by the Medical Research Council.

\section{References}

1 Landis CA, Masters SB, Spada A, Pace AM, Bourne HR \& Vallar L. GTPase inhibiting mutations activate the alpha chain of Gs and stimulate adenylyl cyclase in human pituitary tumours. Nature $1989340692-696$.

2 Pei L \& Melmed S. Isolation and characterization of a pituitary tumor-transforming gene (PTTG). Molecular Endocrinology 1997 $11433-441$.

3 Zhang X, Sun H, Danila DC, Johnson SR, Zhou Y, Swearingen B \& Klibanski A. Loss of expression of GADD45 gamma, a growth inhibitory gene, in human pituitary adenomas: implications for tumorigenesis. Journal of Clinical Endocrinology and Metabolism $2002871262-1267$.

4 Zhang X, Zhou Y, Mehta KR, Danila DC, Scolavino S, Johnson SR \& Klibanski A. A pituitary-derived MEG3 isoform functions as a growth suppressor in tumor cells. Journal of Clinical Endocrinology and Metabolism $2003 \mathbf{8 8} 5119-5126$.

5 Paez-Pereda M, Giacomini D, Refojo D, Nagashima AC, Hopfner U, Grubler Y, Chervin A, Goldberg V, Goya R, Hentges ST et al. Involvement of bone morphogenetic protein 4 (BMP-4) in pituitary prolactinoma pathogenesis through a Smad/estrogen receptor crosstalk. PNAS $2003 \mathbf{1 0 0} 1034-1039$.

6 Goidin D, Kappeler L, Perrot J, Epelbaum J \& Gourdji D. Differential pituitary gene expression profiles associated- to aging and spontaneous tumors as revealed by rat cDNA expression array. Endocrinology $20001414805-4808$.

7 Wood WM, Sarapura VD, Dowding JM, Woodmansee WW, Haakinson DJ, Gordon DF \& Ridgway EC. Early gene expression changes preceding thyroid hormone-induced involution of a thyrotrope tumor. Endocrinology $2002143347-359$.

8 Mohammad HP, Seachrist DD, Quirk CC \& Nilson JH. Reexpression of p8 contributes to tumorigenic properties of pituitary cells and appears in a subset of prolactinomas in transgenic mice that hypersecrete luteinizing hormone. Molecular Endocrinology 2004 $182583-2593$. 
9 Evans CO, Young AN, Brown MR, Brat DJ, Parks JS, Neish AS \& Oyesiku NM. Novel patterns of gene expression in pituitary adenomas identified by complementary deoxyribonucleic acid microarrays and quantitative reverse transcription-polymerase chain reaction. Journal of Clinical Endocrinology and Metabolism 2001 $863097-3107$.

10 Evans CO, Reddy P, Brat DJ, O’Neill EB, Craige B, Stevens VL \& Oyesiku NM. Differential expression of folate receptor in pituitary adenomas. Cancer Research 200363 4218-4224.

11 Morris DG, Kola B, Borboli N, Kaltsas GA, Gueorguiev M, McNicol AM, Ferrier R, Jones TH, Baldeweg S, Powell M et al. Identification of adrenocorticotropin receptor messenger ribonucleic acid in the human pituitary and its loss of expression in pituitary adenomas. Journal of Clinical Endocrinology and Metabolism 200388 6080-6087.

12 Morris DG, Kola B, Grossman AB \& Korbonits M. The optimal endogenous control for human pituitary RNA gene expression studies. In Program of the 85th Annual Meeting of The Endocrine Society, 19-22 June 2003, Philadelphia, PA, pp P2-672, Bethesda: The Endocrine Society Press, 2003.

13 Liu XR, Zhou RL, Zhang QY, Zhang Y, Jin YY, Lin M, Rui JA \& Ye DX. Structure analysis and expressions of a novel tetratransmembrane protein, lysosoma-associated protein transmembrane 4beta associated with hepatocellular carcinoma. World Journal of Gastroenterology 200410 1555-1559.

14 He J, Shao G \& Zhou R. [Effects of the novel gene, LAPTM4B, highly expression in hepatocellular carcinoma on cell proliferation and tumorigenesis of NIH3T3 cells]. Bei-jing Da Xue Xue Bao 200335 348-352.

15 Franklin DS, Godfrey VL, Lee H, Kovalev GI, Schoonhoven R, ChenKiang S, Su L \& Xiong Y. CDK inhibitors p18(INK4c) and p27(Kip1) mediate two separate pathways to collaboratively suppress pituitary tumorigenesis. Genes \& Development $1998122899-2911$.

16 McCabe CJ, Khaira JS, Boelaert K, Heaney AP, Tannahill LA, Hussain S, Mitchell R, Olliff J, Sheppard MC, Franklyn JA \& Gittoes NJ. Expression of pituitary tumour transforming gene (PTTG) and fibroblast growth factor-2 (FGF-2) in human pituitary adenomas: relationships to clinical tumour behaviour. Clinical Endocrinology (Oxford) 200358 141-150.

17 Zhang X, Horwitz GA, Heaney AP, Nakashima M, Prezant TR, Bronstein MD \& Melmed S. Pituitary tumor transforming gene (PTTG) expression in pituitary adenomas. Journal of Clinical Endocrinology and Metabolism $199984761-767$.

18 Musat M, Korbonits M, Kola B, Borboli N, Hanson MR, Nanzer AM, Grigson J, Jordan S, Morris DG, Gueorguiev M et al. Enhanced protein kinase B/Akt signaling in pituitary tumours. Endocrine-related Cancer 2005 (in press).

19 Shao GZ, Zhou RL, Zhang QY, Zhang Y, Liu JJ, Rui JA, Wei X \& Ye DX. Molecular cloning and characterization of LAPTM4B, a novel gene upregulated in hepatocellular carcinoma. Oncogene 200322 5060-5069.

20 Scheithauer B, Horvath E, Lloyd RV \& Kovacs K. Pathology of pituitary adenomas and pituitary hyperplasia. In The Diagnosis and Management of Pituitary Tumors, pp 91-154. Eds K Thapar, K Kovacs, B Scheithauer \& RV Lloyd. Humana Press, 2001.

21 Takayama S, Sato T, Krajewski S, Kochel K, Irie S, Millan JA \& Reed JC. Cloning and functional analysis of BAG-1: a novel Bcl-2-binding protein with anti-cell death activity. Cell 199580 279-284.

22 Wang HG, Takayama S, Rapp UR \& Reed JC. Bcl-2 interacting protein, BAG-1, binds to and activates the kinase Raf-1. PNAS 1996 $937063-7068$

23 Bardelli A, Longati P, Albero D, Goruppi S, Schneider C, Ponzetto C \& Comoglio PM. HGF receptor associates with the anti-apoptotic protein BAG-1 and prevents cell death. EMBO Journal 199615 6205-6212.

24 Takayama S, Krajewski S, Krajewska M, Kitada S, Zapata JM, Kochel K, Knee D, Scudiero D, Tudor G, Miller GJ et al. Expression and location of Hsp70/Hsc-binding anti-apoptotic protein BAG-1 and its variants in normal tissues and tumor cell lines. Cancer Research $1998 \mathbf{5 8} 3116-3131$.

25 Kudoh M, Knee DA, Takayama S \& Reed JC. Bag1 proteins regulate growth and survival of ZR-75-71 human breast cancer cells. Cancer Research 200262 1904-1909.

26 Woloschak M, Yu A, Xiao J \& Post KD. Frequent loss of the P16INK4a gene product in human pituitary tumors. Cancer Research $1996562493-2496$.

$27 \mathrm{Yu}$ WH, Hui GZ, Wang Q \& Wu SR. [Preliminary study of p16 gene expression in pituitary adenomas]. Ai Zheng 200322 198-201.

28 Simpson DJ, Bicknell JE, McNicol AM, Clayton RN \& Farrell WE. Hypermethylation of the p16/CDKN2A/MTSI gene and loss of protein expression is associated with nonfunctional pituitary adenomas but not somatotrophinomas. Genes Chromosomes \& Cancer $199924328-336$.

29 Lidhar K, Korbonits M, Jordan S, Khalimova Z, Kaltsas G, Lu X, Clayton RN, Jenkins PJ, Monson JP, Besser GM et al. Low expression of the cell cycle inhibitor p27Kip1 in normal corticotroph cells, corticotroph tumors, and malignant pituitary tumors. Journal of Clinical Endocrinology and Metabolism 1999 $843823-3830$.

Received 18 January 2005

Accepted 23 March 2005 